\title{
Information Structure Features and Syntax-prosody Mapping of Bangla Embedded Clauses: Implications for Match Theory
}

\author{
Brian Hsu \\ University of Southern California
}

\section{Introduction}

This paper is concerned with the range of syntactic information that is relevant in the mapping from syntactic to prosodic constituent structure. While it is generally accepted in Prosodic Phonology (Selkirk 1981; Nespor and Vogel 1986; Truckenbrodt 1995; Selkirk 2011, among many others) that syntactic phrasehood and certain category distinctions are accessible to the mapping from syntactic to prosodic representations, it is less established whether additional syntactic features are visible. This paper presents data on clausal prosody in Bangla to argue that constraints on syntax-prosody correspondence do make reference to certain non-category features, contra the view of Focus Prominence Theory (Truckenbrodt 1995, 1999; Selkirk 2005, 2007). Specifically, I propose an analysis within Match Theory (Selkirk 2009, 2011; Elfner 2012; Varis 2012) where MATCH constraints that map clauses to intonational phrases only target clausal root nodes (CPs) that bear topic or focus features.

In Bangla, embedded clauses appear in various positions within the main clause. In particular, I discuss contrasts between postverbal embedded clauses, which follow the matrix verb, and preverbal embedded clauses, which precede the matrix verb. Embedded clause position is correlated with discourse interpretation, such that preverbal embedded clauses are either topicalized or focused, while postverbal ones are discourse-neutral. I present new data to show that embedded clause placement also affects their prosodic status: preverbal embedded clauses form intonational phrases while postverbal ones do not. The corresponding prosodic and syntactic representations are given below, where $1(\ldots) t$ indicates intonational phrase boundaries, [ ... ] indicates a syntactic clause, and $\mathrm{S}$ and $\mathrm{V}$ show main clause subjects and main verbs. A postverbal clause is schematically shown in (1), with preverbal clauses in (2) and (3). ${ }^{1}$

$$
\begin{aligned}
& \text { a. } 1(\text { i }) \\
& \text { b. }\left[\begin{array}{lllll}
\mathrm{S} & \mathrm{V} & {[} & \ldots &
\end{array}\right]
\end{aligned}
$$

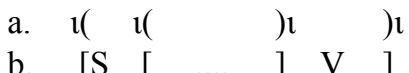

$$
\begin{aligned}
& \text { a. } 1(1(\quad))
\end{aligned}
$$

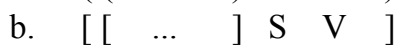

Crucially, the promotion of preverbal embedded clauses to intonational phrases differs from the prosodic realization of focus or topicalization on items that are smaller than clauses, indicating that both syntactic

\footnotetext{
* This work is much indebted to discussions with Andrew Simpson, Karen Jesney, Rachel Walker, Maria Luisa Zubizarreta, Elisabeth Selkirk, and audiences at the 2014 Annual Meeting on Phonology. I also thank Saurov Syed, Arunima Choudhury, and Priyanka Biswas for graciously providing much of the data and judgments. This research has been supported by the Dornsife Doctoral Fellowship.

${ }^{1}$ While these representations show recursive intonational phrasing in preverbal embedded clauses, no critical arguments are presented in favor of or against recursive phrasing. The important observation is that only preverbal embedded clauses are flanked by intonational phrase boundaries. For recent arguments in favor of recursivity in prosodic representation, see Wagner (2005), Selkirk (2011), Elfner (2012), Myrberg (2013).
}

\section{(C) 2015 Brian Hsu}

Proceedings of $A M P 2014$

Completed March 1, 2015 
constituent type and discourse function are relevant to prosodic phrasing. I claim that preverbal embedded clauses are specified with [TOPIC] or [FOCUS] features that project to their CP root nodes, and that only CPs with these specifications can be mapped to intonational phrases. I argue that theories of intonational phrasing where mapping parameters cannot reference both category and information structure features do not adequately account for the observed pattern.

The paper is organized as follows. Section 2 presents the relevant facts about Bangla prosody and clause structure, and the challenges they pose to previous theories of syntax-prosody mapping. Section 3 develops the main proposal; I present a Minimalist view of projections in which a restricted set of noncategory features can project to $\mathrm{CP}$ nodes, making them visible to constraints on syntax-prosody correspondence. I argue that the restriction of MATCH constraints on intonational phrasing to CPs with other discourse specifications makes desirable predictions about variation in embedded clause phrasing. Section 4 discusses implications of the proposal for theories of the syntax-phonology interface.

\section{Core properties of Bangla embedded clauses}

2.1 Embedded clause syntax This section introduces some theoretical background on the syntax of embedded clauses, with specific reference to the link between their placement and their discourse interpretation. While Bangla shows default SOV order in both main and embedded clauses (Dasgupta 1980), declarative, discourse-neutral embedded clauses (under broad focus or new information focus) are postverbal relative to the matrix verb. ${ }^{2}$
a. Meri ki bol-lo?
Mary what say- PST
'What did Mary say?'
b. Meri bol-lo [Monoara es-che]
Mary say-PST Monoara come-PERF
'Mary said that Monoara came'

Unlike Indo-Aryan languages with fixed postverbal embedded clause placement, such as Hindi (Manetta 2012) or Kashmiri (Bhatt 1999), Bangla permits preverbal placement of declarative embedded clauses under certain discourse conditions. Sentence-medial CPs, which follow the main clause subject but precede the main verb, obligatorily bear emphatic or corrective focus (Simpson and Bhattacharya 2003). ${ }^{3}$ As a reflex of this, such orders are more naturally accepted when preceded by kintu 'but.'

$$
\begin{aligned}
& \text { (kintu) Meri [Monoara es-che] bol-lo } \\
& \text { but Mary Monoara come-PERF say-PST } \\
& \text { '(...but) Mary said that Monoara came!' }
\end{aligned}
$$

As noted in Hsu (2014), sentence-initial CPs (6), which precede main clause subjects, differ in their interpretation from sentence-medial CPs. Rather than being focused or emphasized, sentence-initial embedded clauses are perceived as topicalized or representing given information. A clear effect of this restriction is the fact that constituents within sentence-initial CPs cannot be focused (7), whereas focus on clause-internal constituents is possible in both sentence-medial and postverbal CPs.

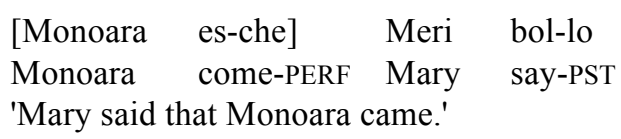

\footnotetext{
${ }^{2}$ Embedded clause placement is additionally constrained by the choice of overt complementizer. Embedded clauses with the initial complementizer $j e$ are obligatorily postverbal, while embedded clauses with the quotative final complementizer bole are obligatorily preverbal (Bayer 2001). This paper restricts its attention to embedded clauses with no null complementizer and those headed by finite and declarative $j e$.

${ }^{3}$ Some speakers require the co-occurrence of a pronoun ( $t a$ or $e T a$ ) in the immediate preverbal position (Bayer 2001).
} 


\begin{tabular}{|c|c|c|c|c|c|}
\hline $\begin{array}{l}* \text { [DADUBHAI } \\
\text { [grandfather }\end{array}$ & $\begin{array}{l}\text { je } \\
\text { that }\end{array}$ & $\begin{array}{l}\text { oSudh } \\
\text { medicine }\end{array}$ & $\begin{array}{l}\text { khey-eche] } \\
\text { eat-PERF] }\end{array}$ & $\begin{array}{l}\text { Jon } \\
\text { John }\end{array}$ & $\begin{array}{l}\text { bol-lo } \\
\text { say-PST }\end{array}$ \\
\hline
\end{tabular}

The restrictions on embedded clause placement reflect the language's general discourse-configurational tendency to place topics in initial positions and focus in medial positions, in both the clausal domain (Simpson and Bhattacharya 2003; Choudhury 2010; Hsu 2014) and nominal domain (Syed 2013). ${ }^{4}$

2.2 Background on Bangla intonational prosody Before presenting the main data and analysis, this section reviews and adopts the comprehensive model of Bangla intonational prosody proposed by Khan (2008), which identifies three levels of prosodic constituency above the word level, the Accentual Phrase (AP), Intermediate Phrase (ip), and Intonational Phrase (IP). We will focus primarily on the distinction between intermediate and intonational phrases.

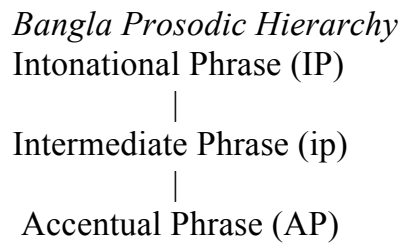

APs correspond roughly to maximal syntactic phrases (XPs), with additional sensitivity to speech rate and directionality of head branching (Hayes and Lahiri 1991). While both ips and IPs are groupings of one or more APs that correspond to larger syntactic units, the parameters that determine their formation have not previously been given a formal account. As a preliminary description, Khan describes postpositional phrases, topics, adverbials, relative clauses, if-clauses, and because-clauses as typical ips. IPs are claimed to correspond more closely to main clauses or full utterances. Assuming that Strict Layering is generally obeyed (Selkirk 1981; Nespor and Vogel 1986), ips and IPs have the same boundaries in simple sentences.

Instances of each category are identifiable by tonal contours, annotated in a Tones and Break Indices model (Silverman et al. 1992; Beckman and Hirschberg 1994) where tones are specified as either high (H) or low (L). Each AP is associated with a pitch accent on its first stressed syllable $\left(\mathrm{T}^{*}\right)$ and a boundary tone at its right boundary (Ta). In standard dialects, APs are typically realized with a low pitch accent and high boundary tone $\left(\mathrm{L}^{*} \ldots \mathrm{Ha}\right)$. The two larger prosodic constituent types share several general properties. Both ips and IPs are associated with boundary tones realized at their right edges ( $\mathrm{T}$ - for ips and T\% for IPs). Both constituents license a larger variety of boundary tones than APs. Boundary tones of different levels do not co-occur; when multiple right boundaries are aligned with each other, the tone of the highest-level category overrides all other tones.

Khan identifies four ip boundary tones: a high tone (H-), low tone (L-), rising contour (LH-), and falling contour (HL-). For the most part, the distinct ip tones do not clearly correspond to interpretational differences; although clause boundaries and interjections seem to be standardly delimited by the low tone, ips corresponding to topics and other given information appear to accept the high, rising, or falling tones.

The right edges of IPs are associated with up to five boundary tones, four of which have similar contours to ip boundary tones. Crucially, however, there is a closer correspondence between the individual tones and discourse interpretations. The low tone (L\%) appears at the end of declarative clauses, the high tone $(\mathrm{H} \%)$ appears as a continuation rise or as an interrogative marker, the rising tone (LH\%) is used in whquestions, and the falling contour (HL\%) indicates yes/no questions. Crucially, the fall and rise boundary tone $(\mathrm{HLH} \%)$, which functions like a continuation rise, is unique to IPs.

Given the similar shapes shared by ip and IP boundary tones, and that both prosodic constituents potentially correspond to syntactic elements of the same size, it is not always straightforward to distinguish boundary strength based on boundary tones alone. However, IPs and ips can further be distinguished by the availability of pauses; Khan notes that pauses are optional at ip edges, but typically obligatory at IP edges.

\footnotetext{
${ }^{4}$ The present discussion remains agnostic with respect to the issue of identifying a single base position for embedded clauses. The head-initial analysis holds that postverbal CPs are in their first-merged position, with preverbal placement derived through raising (Simpson and Bhattacharya 2003). An alternative view holds that the base position is the preverbal object position, with other surface word orders derived by right or left extraposition (Bayer 1996).
} 
The relevant differences between intermediate and intonational phrases are given below.

\begin{tabular}{|c|c|c|}
\hline & Intermediate Phrases & Intonational Phrases \\
\hline $\begin{array}{c}\text { Boundary tone } \\
\text { inventory }\end{array}$ & $\mathrm{H}-, \mathrm{L}-, \mathrm{LH}-, \mathrm{HL}-$ & $\begin{array}{c}\mathrm{H} \%, \mathrm{~L} \%, \mathrm{LH} \%, \\
\mathrm{HL} \%, \mathrm{HLH} \%\end{array}$ \\
\hline Pause availability & optional & obligatory \\
\hline
\end{tabular}

Table 1. Diagnostics for intermediate and intonational phrasing

In the following sections, these diagnostics are used to determine the prosodic status of postverbal and preverbal embedded clauses.

2.2.1 Data The presented data consist of recordings of three native speakers of Kolkata Standard Bangla living in the United States. The recordings were obtained through a reading task where speakers were presented with a list of pre-constructed sentences in Romanized script, containing both the target sentences and items used in a separate study on clitic prosody. They were asked to read at a neutral speech rate with the intonation that would be most natural for the written sentence. Where necessary, contrastive focus was indicated through bolded text. Three tokens of each utterance were recorded, with occasional repetitions due to speaker disfluencies or misreadings. Each speaker was recorded in an indoor room at the University of Southern California, using a built-in microphone on a MacBook Pro laptop computer. All recordings, pitch analysis, and prosodic segmentation were done in Praat (Boersma and Weenink 2011).

Although the informants in the study are speakers of Kolkata Standard Bangla, rather than the Bangladeshi Standard Bangla that was the primary basis of Khan's (2008) analysis, no differences in the realization of tones or in prosodic structure have been observed with respect to the relevant data.

2.2.2 Postverbal embedded clauses form intermediate phrases Consider the waveform and pitch track in (9), which contains a postverbal embedded clause. Several APs can be identified by a standard L*...Ha pitch contour where the pitch peak is aligned with the end of the phrase, as in Monoara, Kamal, and Meri-ke. Following the AP pitch peak on Meri-ke, the pitch fall into the end of the utterance realizes the declarative IP boundary tone L\%. Turning to the embedded clause boundary, the main verb bol-lo does not bear a standard AP boundary tone, but a rising boundary tone indicative of a larger prosodic break.

$$
\begin{array}{llllll}
\text { Monoara } & \text { bol-lo } & \text { [Kamal } & \text { Meri-ke } & \text { nie } & \text { eshe-che] } \\
\text { Monoara } & \text { say-PST } & \text { Kamal } & \text { Mary-ACC } & \text { taken } & \text { come-PERF }
\end{array}
$$

'Monoara said that Kamal brought Mary'

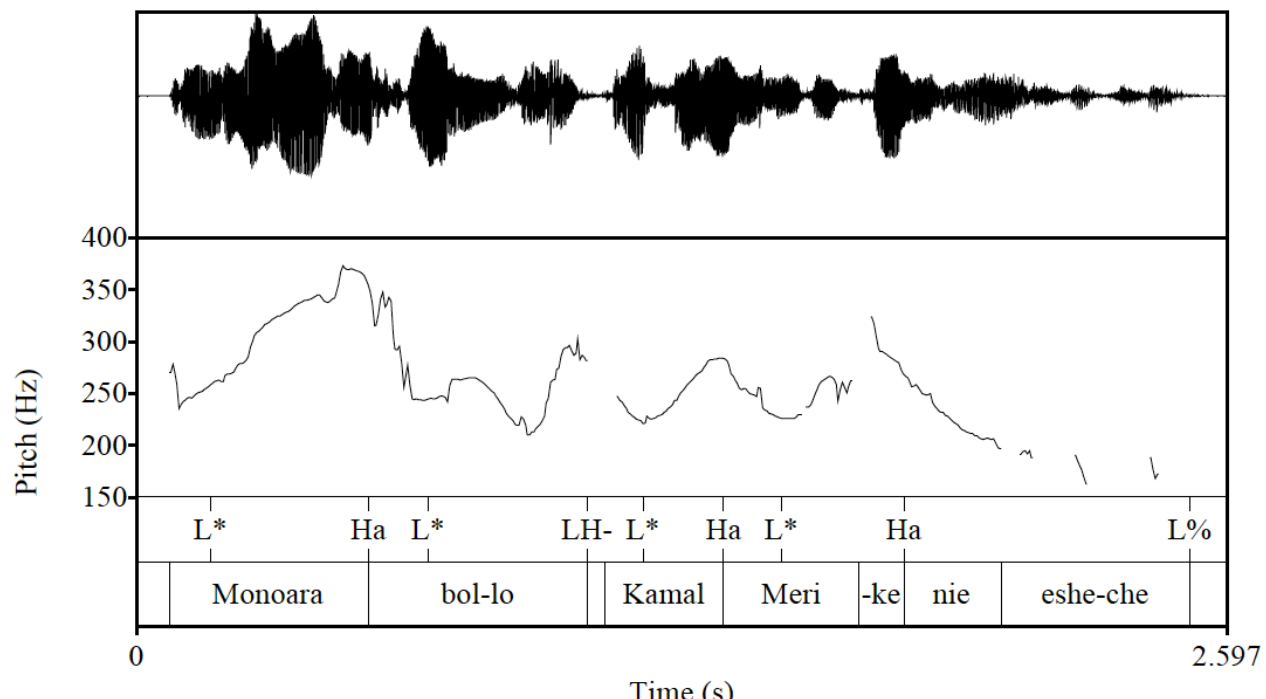

Time (s) 
Further evidence that the postverbal clause boundary is an ip break is the fact that pauses were not produced before postverbal clauses. Furthermore, several of the ip boundary tones (H-, LH-, L-) were produced at the embedded clause breaks (examples omitted for brevity).

\subsubsection{Preverbal embedded clauses form intonational phrases Unlike postverbal embedded} clauses, medial embedded clauses are identified as separate intonational phrases by several diagnostics. The most salient difference is that medial CPs are more naturally separated by short pauses on both ends, as in (10). In this example, both disjunctures are preceded by a high or rising boundary tone.

$$
\begin{array}{lllll}
\text { John [dadubhai je } & \text { kal rate } & \text { oSudh } & \text { khey-eche] } & \text { bol-echi-lo } \\
\text { John grandfather that } & \text { last.night } & \text { medicine } & \text { eat-PERF] } & \text { say-PERF-PST }
\end{array}
$$
'John said that grandfather took medicine last night'

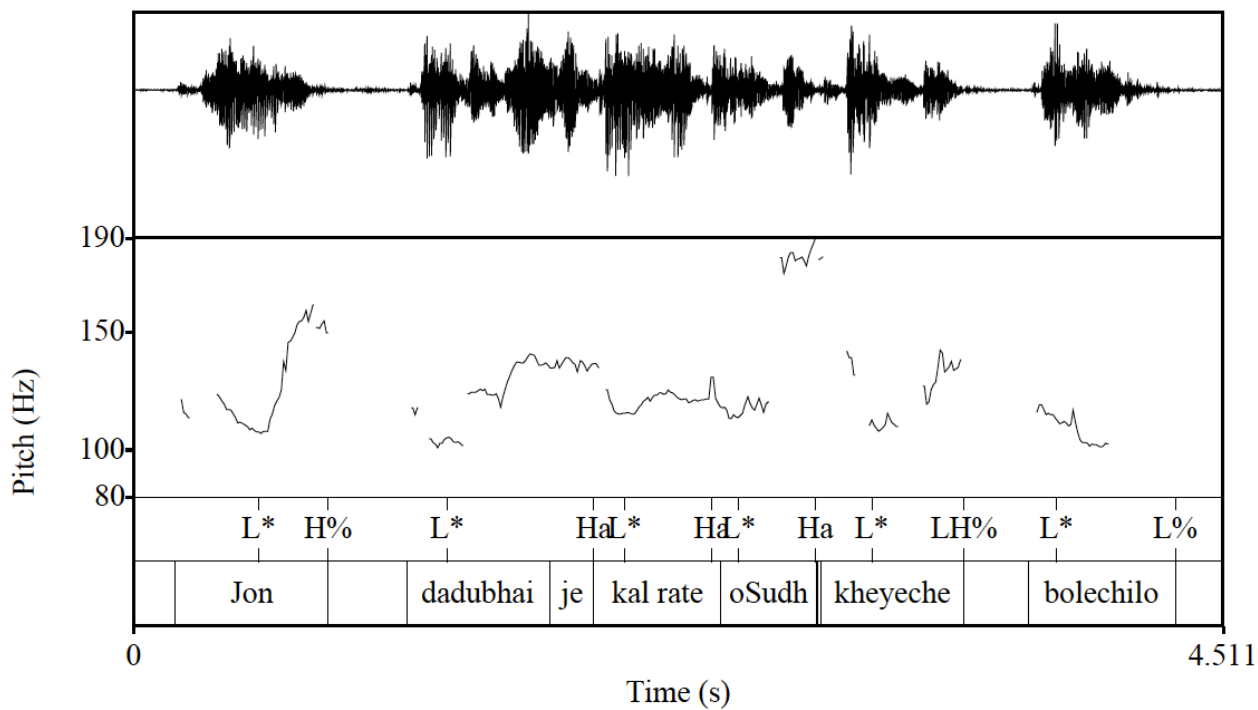

A similar pattern is observed for sentence-initial CPs, confirming that these are also parsed as separate IPs. As shown in (11), the embedded CP is separated from the main clause by a pause after the embedded verb.

$$
\begin{array}{llllll}
\text { [Monoara } & \text { Romila-ke } & \text { nie } & \text { es-che] } & \text { Kamal } & \text { bol-lo } \\
\text { Monoara } & \text { Romila-ACC } & \text { taken } & \text { come-PERF } & \text { Kamal } & \text { say-PST }
\end{array}
$$

'Kamal said that Monoara brought Romila'

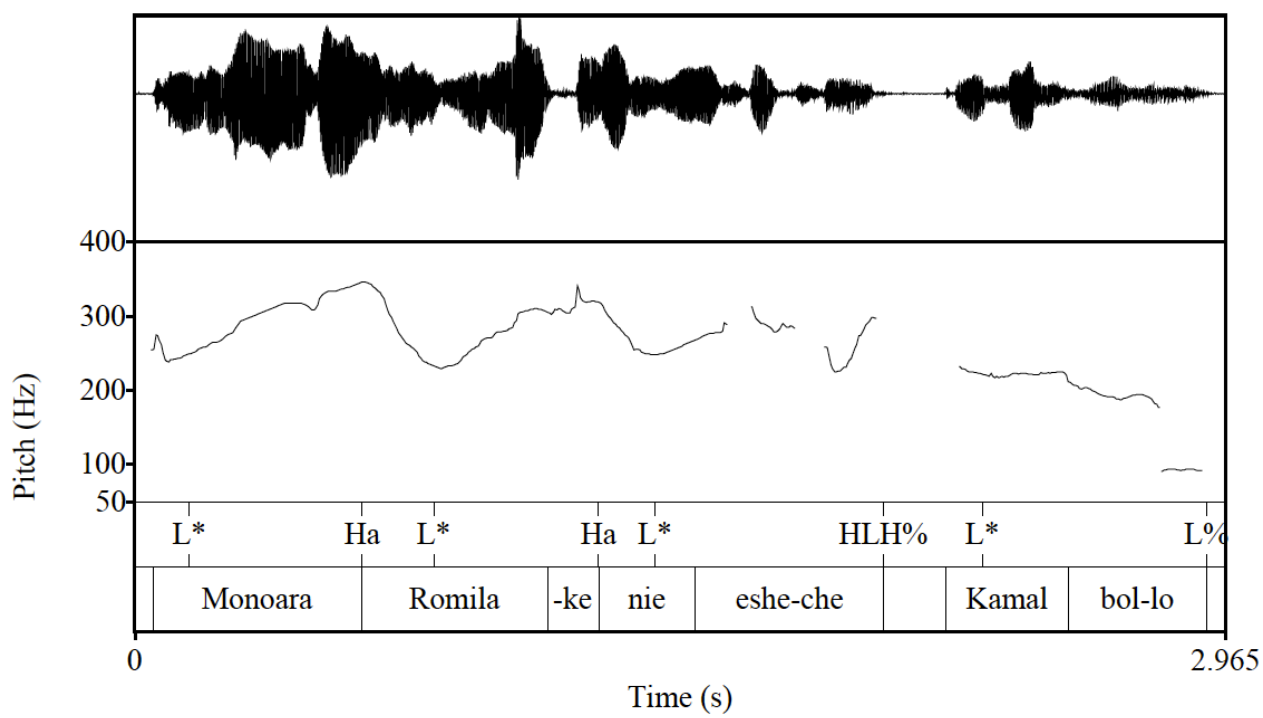


Additional evidence for the IP-status of the embedded clause is seen in the fall and rise boundary tone (HLH\%) realized on the embedded verb nie es-che, a contour unique to IP boundaries. Furthermore, no disjunctures at preverbal clause boundaries were preceded by a low boundary tone (L-), an ip tone attested only at postverbal clause breaks.

It should be noted, however, that pauses are not always present at preverbal clause breaks, particularly at higher speech rates. Consider the following waveform and pitch track where the sentence-medial embedded clause is not marked by discernible pauses. However, there appear to be other cues to the existence of an IP boundary, such as the significant pitch reset that takes place at the left embedded clause boundary. Furthermore, pauses were nonetheless deemed by informants to be more natural at preverbal embedded clause breaks than at postverbal ones.

$$
\begin{aligned}
& \text { Monoara [Kamal Meri-ke nie eshe-che] bol-lo } \\
& \text { Monoara [Kamal Mary-ACC taken come-PERF] say-PST } \\
& \text { 'Monoara said that Kamal brought Mary' }
\end{aligned}
$$

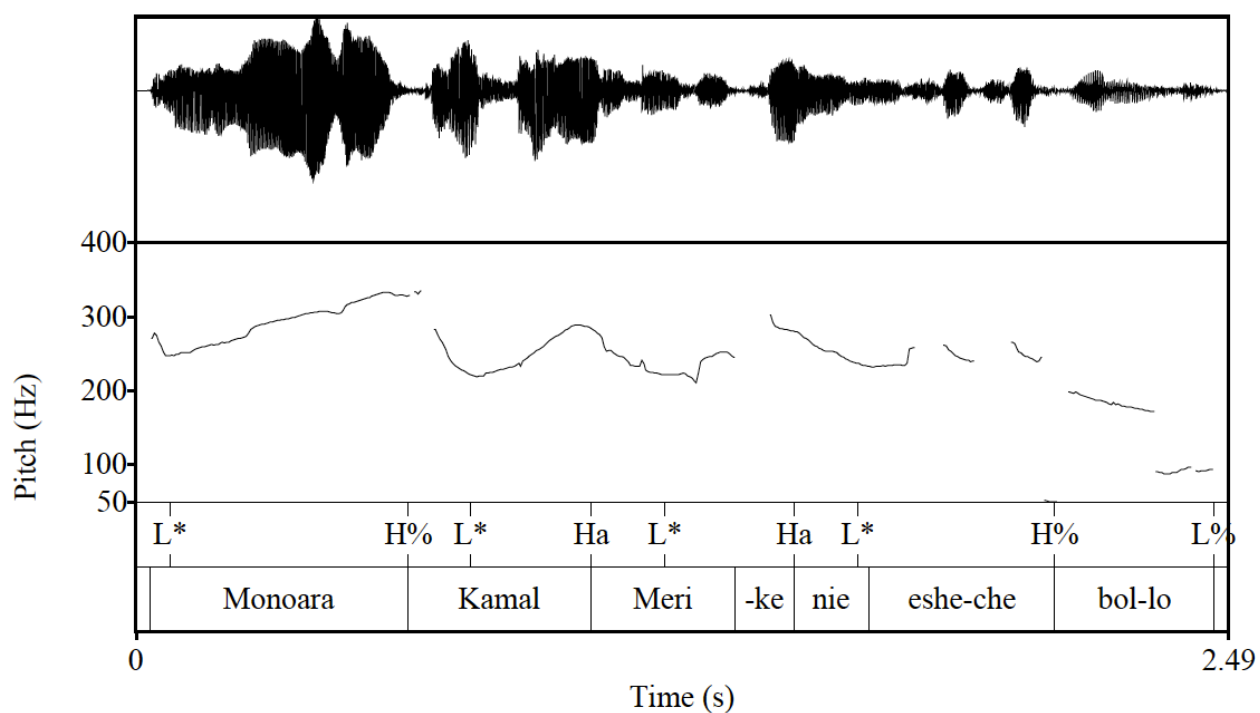

While it appears that pauses are an imperfect diagnostic for intonational phrasing at higher speech rates, the fact that they are spontaneously produced at preverbal clause breaks but not postverbal ones nonetheless suggests that preverbal embedded clauses are of a higher prosodic category.

The analysis of preverbal but not postverbal embedded clauses as full intonational phrases confirms and formalizes judgments reported by Simpson and Bhattacharya (2003) and Bayer and Dasgupta (to appear) that preverbal embedded clauses are separated by larger prosodic breaks than postverbal ones. This is further consistent with the expectation that focused or topicalized constituents, or those that deviate from a neutral word order, may be flanked by larger prosodic boundaries than their neutral counterparts (Odden 1996; Frascarelli 2000; Zubizarreta 2010, among others).

2.3 Difficulties for previous analyses The challenge posed by Bangla is to devise a syntax-prosody mapping parameter that parses preverbal embedded clauses as intonational phrases, while leaving postverbal embedded clauses as intermediate phrases. We first consider why this pattern is not accounted for by previous analyses where prosodic phrasing algorithms make no reference to non-category features.

As a starting point, I adopt the Match framework of syntax-prosody correspondence (Selkirk 2009, 2011). Implemented in an Optimality-Theoretic grammar (Prince and Smolensky 1993), prosodic structure is built from a set of violable MATCH constraints that call for a direct correspondence between syntactic and prosodic constituency. Each MATCH constraint has two arguments, a syntactic constituent and a prosodic category. Previously, it has been assumed that these constraints can reference only syntactic phrasehood ( $\mathrm{X}^{\max }$ phrases vs. $\mathrm{X}^{\circ}$ heads) and certain category distinctions, such as those between lexical and functional projections (see Selkirk 1996 for arguments in an Align approach, Varis 2012 in Match Theory).

Clearly, there is no single MATCH constraint that derives the difference in phrasing between preverbal 
and postverbal embedded clauses. Under the assumption that all embedded clauses are syntactic constituents of the same type (e.g. CPs), no MATCH constraint would require preverbal CPs to correspond to intonational phrases, but postverbal CPs to correspond to intermediate phrases. A similar problem arises within the Alignment approach to syntax-prosody correspondence (Selkirk 1986, 1996), where only the right or left edges of syntactic constituents are accessible to mapping parameters. Specifically, no ALIGN$\mathrm{R} / \mathrm{L}$ setting places IP boundaries at both edges of sentence-medial embedded clauses.

The difference would potentially receive an explanation if preverbal and postverbal embedded clauses are distinct syntactic categories within an extended CP domain (Rizzi 1997), a simplified version of which is given in (13). For example, to account for why main clauses form intonational phrases while embedded clauses typically do not, Selkirk (2009) proposes that main clauses (which carry illocutionary force) project to ForcePs, the largest constituent within the extended CP, while embedded clauses project to a smaller Fin(iteness)P.

$$
[\text { Force } \quad[\text { TopicP } \quad[\text { FocusP } \quad[\text { FinitenessP }[\ldots
$$

Under this approach, the difference between main and embedded clauses is accounted for by subjecting ForcePs and FinPs to distinct MATCH constraints; ForcePs are mapped to intonational phrases by MATCH(ForceP, IP), while FinPs are visible only to MATCH(FinP, ip). This line of analysis, however, cannot straightforwardly be applied to the distinction between preverbal and postverbal embedded clauses, given a common interpretation of the split $\mathrm{CP}$ hypothesis where ForceP and FinP are necessary components to all embedded clauses. Further evidence that both preverbal and postverbal clauses project to ForcePs is the fact that both embedded clause types can be introduced by the complementizer je, specified as both finite (a Fin specification) and declarative (a Force specification).

$$
\begin{array}{llll}
\text { Jon jane } \quad[j e \text { ma } & \text { oSudh } & \text { khey-eche }] \\
\text { John knows that mother medicine } & \text { eat-PERF } \\
\text { 'John knows that mother took medicine.' }
\end{array}
$$

$$
\begin{array}{lllll}
\text { Jon } & \text { ma je } & \text { oSudh } & \text { khey-eche }] & \text { jane } \\
\text { John mother that } & \text { medicine } & \text { eat-PERF } & \text { knows } \\
\text { 'John knows that mother took medicine.' } &
\end{array}
$$

Under the assumption that this dual semantic specification is derived compositionally through head movement (Rizzi 1997; Roberts 2004), it must be the case that je moves from Fin to Force.

If both preverbal and postverbal embedded clauses are of the same syntactic category, it appears that the IP status of preverbal embedded clauses must be due to some kind of topicalization or focus-marking. However, it is crucial to note that the difference in phrasing between postverbal and preverbal clauses cannot be uniquely attributed to the presence of [FOCUS] or [TOPIC] features, with no reference to their status as clauses (section 4 considers one such analysis in more detail). The issue is that the prosodic realization of focus depends on the size of the focused item; focus on a sub-clausal constituent (e.g. an NP) is realized by parsing the focused item as an AP (accentual phrase) marked by a focus high tone (fHa), typically upstepped from preceding high tones, followed by post-focal AP deletion or pitch compression (Hayes and Lahiri 1991; Lahiri and Fitzpatrick-Cole 1999; Selkirk 2007; Khan 2008). The following pitch track shows the effect of focus on the noun dadubhai 'grandfather' within a postverbal embedded clause.

$$
\begin{array}{llllll}
\text { Jon } & \text { bol-echi-lo } \quad[\mathrm{je} & \text { DADUBHAI } & \text { kal rate } & \text { oSudh } & \text { khey-eche } \\
\text { John } & \text { say-PERF-PST that } & \text { grandfather } & \text { last.night } & \text { medicine } & \text { eat-PERF }
\end{array}
$$

'John said that GRANDFATHER took medicine last night.'

\footnotetext{
${ }^{5}$ Postverbal and preverbal embedded clauses differ, however, in where the complementizer je can be placed; it is obligatorily clause-initial in postverbal embedded clauses, and obligatorily non-initial in preverbal embedded clauses. For analyses of the non-initial je restriction in terms of contrast-driven fronting, see Bhattacharya (2001) and Bayer and Dasgupta (to appear). Hsu (2014) analyzes non-initial je as the result of lower copy spell-out due to a prosodic constraint.
} 


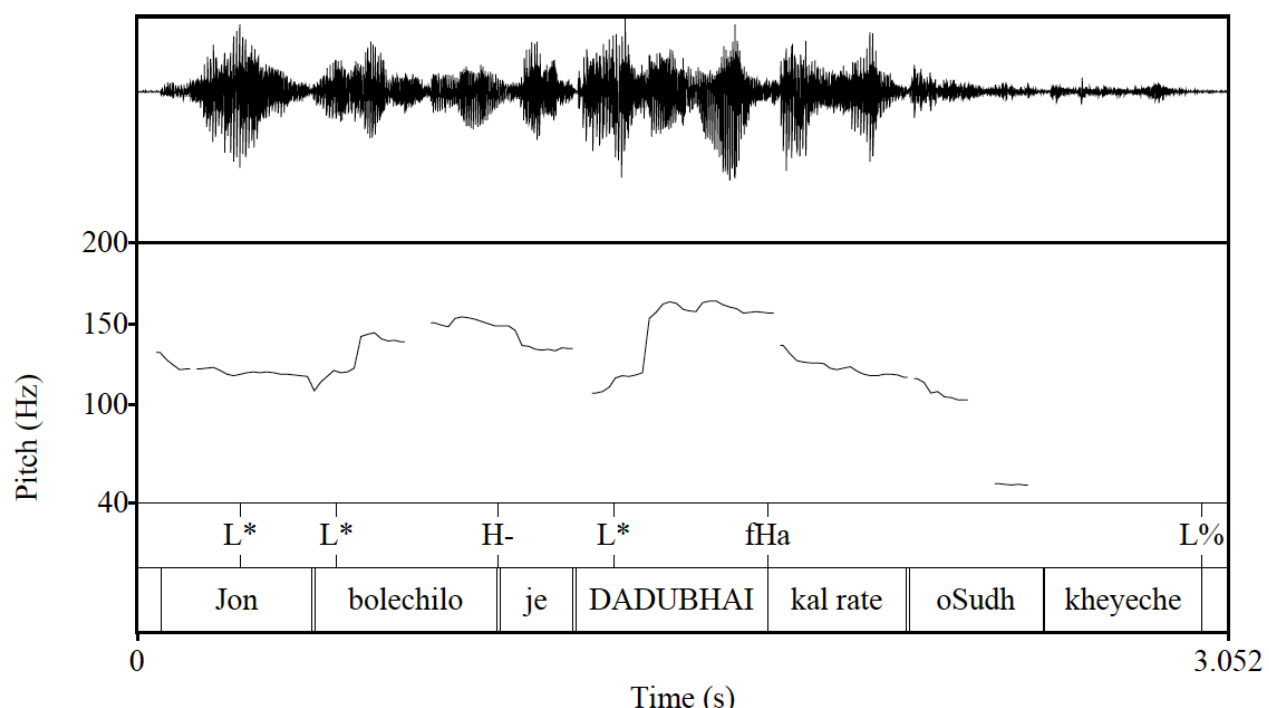

While the prosodic realization of non-clausal topics has received comparatively little description, there is preliminary evidence to believe that they are phrased as ips, rather than IPs (Khan 2008). We should therefore conclude that a proper description of embedded clause phrasing requires reference to both category type (minimally, a clause vs. non-clause distinction) and discourse specification. Such an analysis is presented in the next section.

\section{The role of features in syntax-prosody mapping}

I propose to derive the attested Bangla phrasings through a modification of the universal inventory of MATCH constraints. Specifically, MATCH constraints that map clauses to intonational phrases must be associated with $\mathrm{CP}$ root nodes that bear certain information structure specifications (FOCUS, TOPIC, WH, etc.). Furthermore, I propose that the visibility of non-category features to MATCH constraints is a natural consequence of the theory of projections formalized by Adger (2003) and Di Sciullo and Isac (2008).

The key claim within this approach is that when two constituents are Merged (Chomsky 1993, 1995, et seq.) the label of the newly formed root node is determined by which of its daughters contains unchecked features. Consider the following abstract example where some head $\mathrm{X}$ selects a complement $\mathrm{Y}$. Both heads are specified with their own category features, $[\mathrm{X}]$ and $[\mathrm{Y}] . \mathrm{X}$ is additionally specified with an uninterpretable category-selection feature $[u \mathrm{Y}]$. Merge triggers the checking of the category-selection feature $[u \mathrm{Y}]$ with $[\mathrm{Y}]$, deleting them from the representation. Since the category feature $[\mathrm{X}]$ is the only one that remains unchecked, it projects to the newly formed root node. In other words, the label XP is the notational representation of a projection headed by unchecked [X].

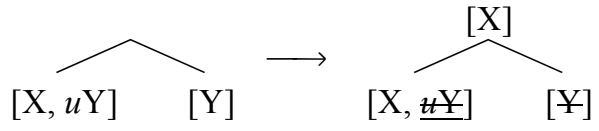

Turning to a more concrete example, we assume that each embedded clause corresponds to a CP, created after a complementizer $\mathrm{C}$ is Merged with a phrase containing the inflectional domain of the clause, TP.

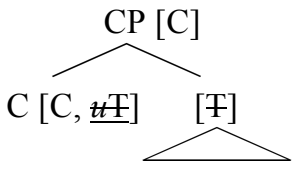

The key to the present proposal is that since unchecked category features project to the root node, the null hypothesis is that any additional unchecked features of heads will also project. I propose that in 
addition to their category and category-selectional features, Bangla complementizers can bear either [FOCUS] or [TOPIC] features that also project to the newly formed root node (cf. Selkirk 1984 on the projection of focus from heads to phrases). Under an analysis where embedded clauses are first generated postverbally, the [FOCUS] and [TOPIC] features may trigger fronting of the CP to a preverbal position.

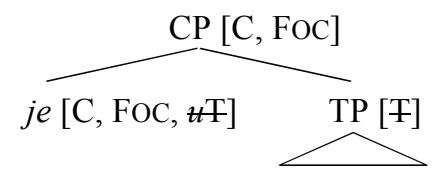

I assume that the only features that can project to the clausal root node are those that have been merged in $\mathrm{C}$ (or any head in the extended complementizer domain). ${ }^{6}$ Thus, while non-category features relating to clause type (e.g. [WH]) and discourse interpretation (e.g. [TOP], [FOC]) may project to the CP node, features that must be checked further down in the clause's inflectional domain (e.g. case and phi-features) can not.

The difference in prosodification between postverbal and preverbal CPs is thus explained as follows. Only clausal root nodes with the pairs of features $[\mathrm{C}, \mathrm{FOC}]$ or $[\mathrm{C}, \mathrm{TOP}]$ are be mapped to IPs, while root nodes with only the category feature [C] are mapped to ips. I propose that this results from a restriction on the universal constraint set CON (Prince and Smolensky 1993). MATCH constraints that map clauses to intonational phrases must make reference to root nodes these pairs of features, while CPs that lack these additional specifications are visible only to constraints on intermediate phrasing. In other words, the Bangla pattern is the result of the following constraint inventory (constraint schema adapted from Elfner 2012):

$\operatorname{MATCH}([\mathrm{C}, \mathrm{FOC}], \mathrm{IP})$

For each root node in the input syntactic representation that bears both [C] and [FOC] features, there is an intonational phrase (IP) in the output phonological representation that dominates all phonological exponents of the terminal nodes dominated by the $[\mathrm{C}, \mathrm{FOC}]$ root node.

$\operatorname{MATCH}([\mathrm{C}, \mathrm{TOP}], \mathrm{IP})$

For each root node in the input syntactic representation that bears both [C] and [TOP] features, there is an intonational phrase (IP) in the output phonological representation that dominates all phonological exponents of the terminal nodes dominated by the $[\mathrm{C}, \mathrm{TOP}]$ root node.

\section{$\operatorname{MATCH}([\mathrm{C}], \mathrm{ip})$}

For each root node in the input syntactic representation that bears a [C] feature, there is an intermediate phrase (ip) in the output phonological representation that dominates all phonological exponents of the terminal nodes dominated by the $[\mathrm{C}]$ root node.

As with previous uses of MATCH constraints, each constraint only "sees" the phonological exponents (presumably already linearized) of terminal nodes dominated by the targeted root node, and makes no reference to additional syntactic structure or hierarchical relations. It is important to reiterate that features that are checked below the clausal domain will not project to $\mathrm{CP}$ root nodes, making them predictably irrelevant to MATCH constraints on CP-phrasing.

This restriction on clause-level MATCH constraints explains the cross-linguistic observation that neutral embedded clauses are typically parsed not as intonational phrases, but as an intermediate constituent. It may also explain the relatively close correspondence in Bangla between specific IP boundary tones and discourse structure, observed to a lesser degree with ip boundary tones (Khan 2008). It remains unresolved whether any non-category feature associated with the CP node can trigger the creation of an IP boundary, or whether there is language-specific variation in the features that do so. In the latter case, one might expect languages where topicalized clauses form intonational phrases, but not focused clauses. I leave this question to be clarified by further study of syntax-prosody correspondence according to clause type.

\footnotetext{
${ }^{6}$ Existing proposals in this approach leave unresolved the question of how far upwards unchecked non-category features can project. As a tentative answer, it may be that these features do not project beyond the first phasal node (Chomsky 2000) that contains them.
} 
Given this constraint inventory, a natural question that arises is why simple declarative sentences nonetheless form intonational phrases, given the suggestion that declarative main clauses are unmarked for interpretational features (Roberts 2004). Following Selkirk (1996), this is due to the inviolability of HEADEDNESS, which requires all prosodic categories to dominate at least one constituent of the lower level of the Prosodic Hierarchy. Because each utterance must dominate an intonational phrase, all matrix clauses will be parsed as intonational phrases even in the absence of constraints that require this correspondence.

\section{Discussion}

We can consider an alternative approach based on Focus Prominence Theory (Truckenbrodt 1995, 1999; Selkirk 2005, 2007), which derives the Bangla phrasing through the interaction of two types of constraints, syntax-prosody mapping constraints (e.g. MATCH, WRAP) and markedness constraints on prosodic representations, only the latter of which access the phonological exponents of syntactic features (e.g. focus prominence). In this framework, a basic analysis of Bangla phrasing might go as follows. By default, all embedded clauses are mapped to intermediate phrases, due to the constraint $\operatorname{MATCH}(\mathrm{CP}$, ip). However, topicalization or contrastive focus of an embedded clause requires the realization of an IP boundary tone, for example, HLH\%. Since the contour tone can be realized only at an IP boundary, the focused embedded clause is promoted to an intonational phrase. We can generate the pattern using the following constraints (LOCALITY-FOCUS corresponds to SYNTAX-FAITH in the analysis of Selkirk 2007):

ALIGN-R([HLH\% $]_{\text {Foc }}$, IP)

A $[\mathrm{HLH} \%]_{\mathrm{Foc}}$ boundary tone is aligned with the right-most tone-bearing element of an intonational phrase.

\section{LOCALITY-FOCUS}

Focus is realized on a phonological exponent of its focus-marked constituent.

\section{$\operatorname{MATCH}([\mathrm{C}]$, ip)}

For each root node in the input syntactic representation that bears a [C] feature, there is an intermediate phrase (ip) in the output phonological representation that dominates all phonological exponents of the terminal nodes dominated by the $[\mathrm{C}]$ root node.

The desired result is obtained by the ranking Align-R([HLH $]_{\mathrm{Foc}}$, IP), LOCALITY-FOCUS $>>$ MATCH([C], ip).

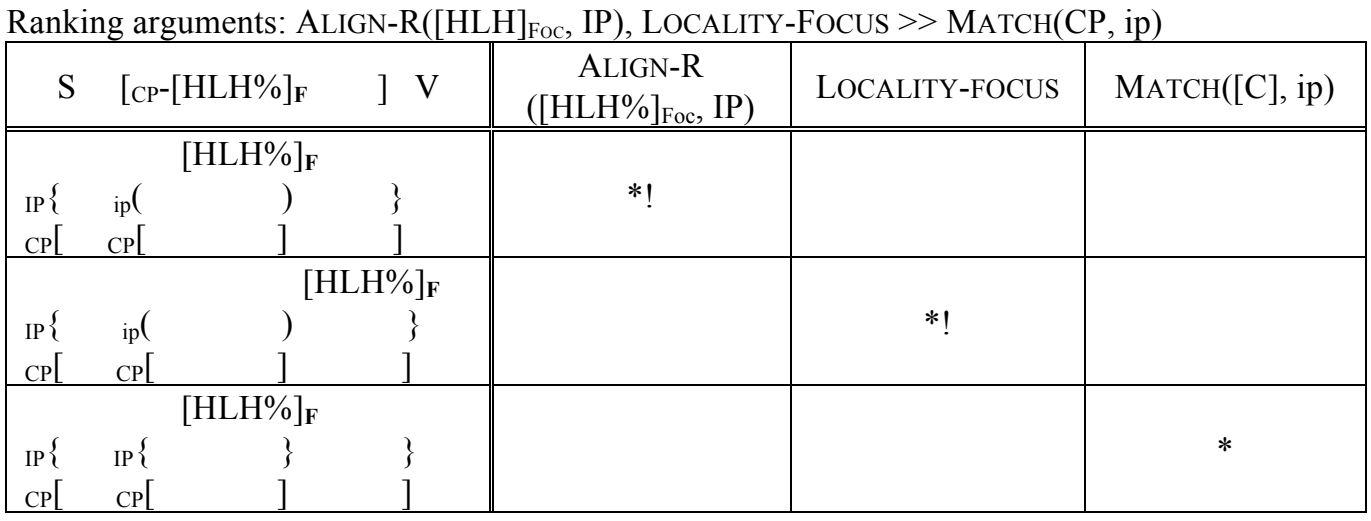

While the interaction of syntax-prosody mapping constraints with markedness constraints on prosodic representations successfully accounts for the Bangla pattern, some theoretical issues remain with this type of analysis. The first concerns the fact that the locality condition on the prosodic marking of information structure (implemented as LOCALITY-FOCUS) appears to be inviolable; that the prosodic realization of a discourse function always falls on part of the corresponding syntactic constituent seems to be a hard constraint on the syntax-prosody interface. If this is the case, it suggests a more direct correspondence between phrasing and discourse structure. The second issue is the fact that there is no clear way to restrict 
the types of features that can impose boundary tones associated with various prosodic constituents; it must be stipulated that HLH\% boundary tones can be associated with topicalized or focused embedded clauses, but not subclausal constituents (cf. section 2.3). This distinction is more straightforwardly accounted for if syntax-prosody mapping constraints can directly refer to both category label and discourse features.

To conclude, the aim of this paper is not to deny the interaction of syntax-prosody correspondence constraints with other constraints on prosodic well-formedness, nor to argue that all intonational phrasing should be attributed to MATCH constraints of some kind. Rather, it argues against a proposed restriction against direct reference to non-category syntactic features by syntax-prosody mapping constraints; it claims that the abandonment of this restriction maintains strong empirical coverage, and is consistent with a Minimalist theory of projections. Similar proposals in favor of feature reference by mapping constraints have been made by Smith $(2005,2011)$ and Richards $(2010)$, who show that [WH] features must be visible to constraints on syntax-prosody alignment. For instance, Smith (2011) proposes that phrasing in Fukuoka Japanese is derived by a WRAP constraint (Truckenbrodt 1995) that requires every complementizer with a [WH] feature to be in the same phonological phrase as its associated $w h$-word. Crucially, such a constraint requires reference to both a head of a certain category and an additional featural specification.

Although the proposal has focused on the phrasing of clauses, it suggests that constraints on syntaxprosody alignment should also be able to access non-category features of other types of syntactic phrases. There is indeed preliminary evidence to this effect in the nominal domain. Kisseberth and Abasheikh (2011) propose that noun phrasing in Chimwiini is dependent on definiteness; only indefinite nouns are followed by a prosodic phrase boundary, while definite nouns are not. Similarly, Soh (2001) argues that phrase formation in Shanghai Chinese and Hokkien/Xiamen Chinese ignores [-DEFINITE] DPs. Although such facts merit a more thorough examination, they suggest that the connection between prosodic phrasing and syntactic features is tighter than typically assumed in the standard theory.

\section{References}

Adger, David. 2003. Core Syntax : A Minimalist Approach. Oxford: Oxford University Press.

Bayer, Josef. 1996. Directionality and Logical Form. Boston: Kluwer.

Bayer, Josef. 2001. Two grammars in one: sentential complements and complementizers in Bengali and other SouthAsian languages. In The Yearbook of South Asian Languages: Tokyo Symposium on South Asian Languages Contact, Convergence, and Typology, ed. P. Bhaskarorao and K. V. Subbarao, 11-36. New Delhi: Sage Publications.

Bayer, Josef, and Probal Dasgupta. To appear. Emphatic Topicalization and the structure of the left periphery: Evidence from German and Bangla. To appear in Syntax.

Beckman, Mary, and Julia Hirschberg. 1994. The ToBI Annotation Conventions. Ms., Ohio State University

Bhatt, Rakesh. 1999. Verb movement and the syntax of Kashmiri. Dordrecht: Kluwer.

Bhattacharya, Tanmoy. 2001. Peripheral and clause-internal complementizers in Bangla: A case for remnant movement. Proceedings of WECOL 2000 12: 1-14.

Boersma, Paul, and David Weenink. 2011. Praat: doing phonetics by computer (version 5.2.23). Computer Program. http://www.praat.org/.

Chomsky, Noam. 1993. A minimalist program for linguistic theory. In The View from Building 20, ed. Kenneth Hale and Samuel Jay Keyser, 1-52. Cambridge, MA: MIT Press.

Chomsky, Noam. 1995. The Minimalist Program. Cambridge, MA: MIT Press.

Chomsky, Noam. 2000. Minimalist inquiries: the framework. In Step by Step: essays on Minimalist syntax in honour of Howard Lasnik, ed. Roger Martin, David Michaels, Juan Uriagereka, and Samuel Jay Keyser, 89-115. Cambridge, MA: MIT Press.

Choudhury, Arunima. 2010. A Study of Focus in Bangla. University of Southern California.

Dasgupta, Probal. 1980. Questions and relative and complement clauses in a Bangla grammar. Ph.D dissertation, New York University.

Elfner, Emily. 2012. Syntax-Prosody Interactions in Irish. Ph.D dissertation, University of Massachusetts, Amherst.

Frascarelli, Mara. 2000. The Syntax-Phonology Interface in Focus and Topic Constructions in Italian. Dordrecht: Kluwer Academic Publishers.

Hayes, Bruce, and Aditi Lahiri. 1991. Bengali intonational phonology. Natural Language \& Linguistic Theory 9: 4796.

Hsu, Brian. 2014. Variation in Bangla complementizer order: The effect of intonational phrasing. Ms., University of Southern California. 
Khan, Sameer ud Dowla. 2008. Intonational Phonology and Focus Prosody of Bengali. Ph.D dissertation, University of California, Los Angeles.

Kisseberth, Charles W. and Mohammed Imam Abasheikh. 2011. Chimwiini phonological phrasing revisited. Lingua 121: 1987-2013.

Lahiri, Aditi, and Jennifer Fitzpatrick-Cole. 1999. Emphatic Clitics and Focus Intonation in Bengali. In Phrasal Phonology, ed. René Kager and Wim Zonneveld, 119-144. Nijmegen: University of Nijmegen Press.

Manetta, Emily. 2012. Reconsidering rightward scrambling: Postverbal constituents in Hindi-Urdu. Linguistic Inquiry 43: 43-74.

Myrberg, Sara. 2013. Sisterhood in prosodic branching. Phonology 30: 73-124.

Nespor, Marina, and Irene Vogel. 1986. Prosodic Phonology. Dordrecht: Foris.

Odden, David. 1996. The Phonology and Morphology of Kimatuumbi. Oxford: Oxford University Press.

Prince, Alan, and Paul Smolensky. 1993. Optimality Theory: Constraint Interaction in Generative Grammar. Ms., Rutgers University \& University of Colorado, Boulder. Published 2004, Malden, MA: Blackwell.

Richards, Norvin. 2010. Uttering Trees. Cambridge, MA: MIT Press.

Rizzi, Luigi. 1997. The fine structure of the left periphery. In Elements of Grammar, ed. Liliane Haegeman, $281-337$. Dordrecht: Kluwer.

Roberts, Ian G. 2004. The C-System in Brythonic Celtic Languages, V2, and the EPP. In The Structure of CP and IP, ed. Luigi Rizzi, 297-328. Oxford: Oxford University Press.

Di Sciullo, Anna Maria, and Daniela Isac. 2008. The Asymmetry of Merge. Biolinguistics 2: 260-290.

Selkirk, Elisabeth. 1981. On the nature of phonological representation. In The Cognitive Representation of Speech, ed. John Anderson, John Laver, and Terry Meyers. Amsterdam: North Holland.

Selkirk, Elisabeth. 1984. Phonology and Syntax: The Relation Between Sound and Structure. Cambridge, MA: MIT Press.

Selkirk, Elisabeth. 1986. On derived domains in sentence phonology. Phonology Yearbook 3: 371-405.

Selkirk, Elisabeth. 1996. The Prosodic Structure of Function Words. In Signal to Syntax: Bootstrapping from Speech to Grammar in Early Acquisition, ed. James L. Morgan and Katherine Demuth, 187-214. Mahwah, NJ: Lawrence Erlbaum Associates.

Selkirk, Elisabeth. 2005. Comments on Intonational Phrasing in English. In Prosodies, ed. Sonia Frota, Marina Vigario, and Maria Joao Freitas, 11-58. Berlin: Mouton de Gruyter.

Selkirk, Elisabeth. 2007. Bengali intonation revisited: An optimality theoretic analysis in which Focus stress prominence drives Focus p. In Topic and Focus: Cross-Linguistic Perspectives on Meaning and Intonation, ed. Chungmin Lee and Matthew Gordon, 6:215-244. Springer.

Selkirk, Elisabeth. 2009. On Clause and Intonational Phrase in Japanese: The Syntactic Grounding of Prosodic Constituent Structure. Gengo Kenkyu: 1-39.

Selkirk, Elisabeth. 2011. The Syntax-Phonology Interface. In The Handbook of Phonological Theory, ed. John Goldsmith, Jason Riggle, and Alan Yu, 2nd ed., 1-66. Oxford: Blackwell.

Silverman, Kim, Mary Beckman, John Pitrelli, Mori Ostendorf, Colin W. Wightman, Patti Price, Janet Pierrehumbert, and Julia Hirschberg. 1992. ToBI: A standard scheme for labeling prosody. Proceedings of the Second International Conference on Spoken Language Processing: 867-870.

Simpson, Andrew, and Tanmoy Bhattacharya. 2003. Obligatory overt Wh-movement in a Wh-in-situ language. Linguistic Inquiry 34: 127-142.

Smith, Jennifer L. 2005. Some Implications for the Syntax-Prosody Interface. In Papers on Prosody, UMOP 30, ed. Shigeto Kawahara. Amherst, MA: GLSA.

Smith, Jennifer L. 2011. [+wh] complementizers drive phonological phrasing in Fukuoka Japanese. Natural Language \& Linguistic Theory 29: 545-559.

Soh, Hooi Ling. 2001. The Syntax and Semantics of Phonological Phrasing in Shanghai and Hokkien. Journal of East Asian Linguistics 10: 37-80.

Syed, Saurov. 2013. DP-Internal Focus and Topic in Bangla. In Online Proceedings of GLOW in Asia IX, ed. Nobu Goto, Koichi Otaki, Atsushi Sato, and Kensuke Takita. Mie University.

Truckenbrodt, Hubert. 1995. Phonological Phrases: Their Relation to Syntax, Focus, and Prominence. Ph.D dissertation, Massachusetts Institute of Technology.

Truckenbrodt, Hubert. 1999. On the Relation between Syntactic Phrases and Phonological Phrases. Linguistic Inquiry 30: 219-255.

Varis, Erika Elizabeth. 2012. The Spanish feminine el at the syntax-phonology interface. Ph.D dissertation, University of Southern California.

Wagner, Michael. 2005. Prosody and Recursion. Ph.D dissertation, Massachusetts Institute of Technology.

Zubizarreta, María Luisa. 2010. The Syntax and Prosody of Focus : The Bantu-Italian Connection. Iberia 2: 131-168. 